Supporting Information for:

\title{
Using $J_{\mathrm{PP}}$ to Identify Ni Bidentate Phosphine Complexes In Situ
}

Matthew D. Hannigan, ${ }^{\ddagger}$ Anne J. McNeil, ${ }^{\ddagger \dagger}$ and Paul M. Zimmerman ${ }^{\ddagger \star}$

‡Department of Chemistry, University of Michigan, 930 North University Avenue, Ann Arbor, MI 48109-1055, United States

† Macromolecular Science and Engineering Program, University of Michigan, 2800 Plymouth Road, Ann Arbor, MI 48109-2800, United States

\section{Table of Contents}

I. Dataset construction and processing............................................................................................. S2

a. 2-carbon complexes....................................................................................................................................... S2

b. 3-carbon complexes........................................................................................................................... S4

c. Manual data processing.......................................................................................................................... S6

II. Correlations with experimental ${ }^{31} \mathrm{P}$ chemical shift.................................................................. S8

III. Computational details......................................................................................................................... S10

a. Geometry optimization............................................................................................................... S10

b. ISSC (J-coupling) calculations..................................................................................................... S10

c. Charge transfer calculations with ALMOs................................................................................. S14

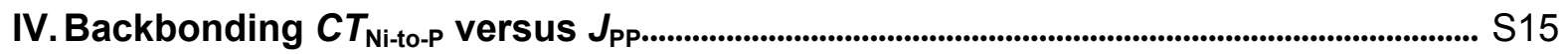

V.Correlations with bite angle and linker identity..................................................................... S16

VI. References.................................................................................................................................................................. S20 


\section{Dataset construction and processing}

All of the Ni bidentate phosphine complexes used in this analysis were reported in the literature before December $22^{\text {nd }} 2020$. The process used to identify complexes is described below.

\section{a. 2-carbon linker dataset:}

The complexes containing 2-carbon linkers were found via a substructure search of the Reaxys database. The MarvinJS structure editor was used, and the specific structure query is shown in Figure S1.

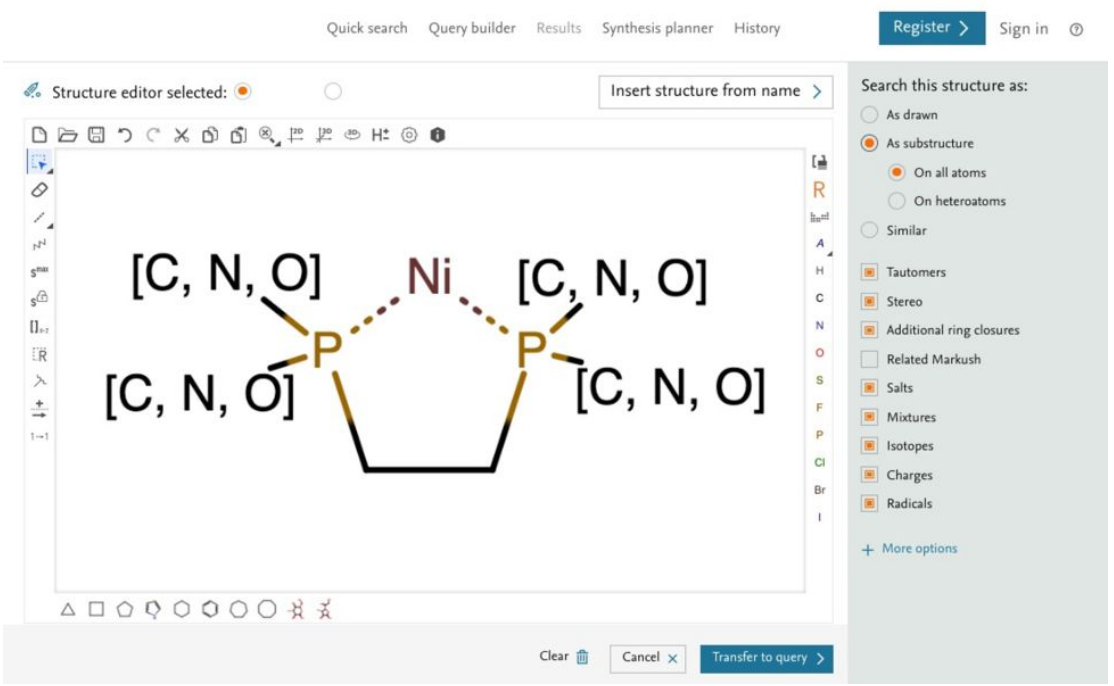

Figure S1. The query used for identifying complexes with 2-carbon backbones. The dotted bonds between $\mathrm{P}$ and Ni correspond to "any" bond. The [C,N,O] group attached to the P atoms enables search for structures with $\mathrm{P}-\mathrm{C}, \mathrm{P}-\mathrm{N}$, and $\mathrm{P}-\mathrm{O}$ bonds.

The results of this query were limited to structures that contain "Interatomic Distances and Angles" (Figure S2) as available data, effectively narrowing the dataset to complexes that have single-crystal X-ray diffraction structures reported. This dataset had 812 complexes.

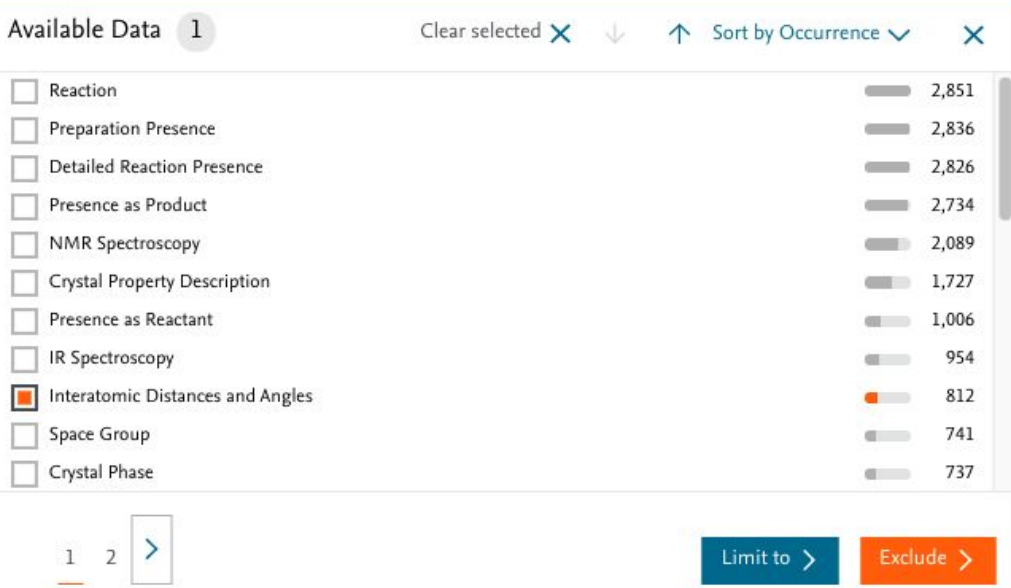

Figure S2. Narrowing the query results by using available data; specifically, only those substances that contain single-crystal X-ray structures by selecting only "Interatomic Distances and Angles". 
An additional filter was applied to limit the dataset to complexes that contain "NMR Spectroscopy" (Figure S3) as available data, narrowing the dataset to complexes that have been analyzed by NMR spectroscopy (although, this includes NMR spectra of any nucleus). This dataset had 509 complexes.

\begin{tabular}{|c|c|c|c|c|}
\hline Available Data 1 & Clear selected $X$ & $\downarrow \uparrow$ & Sort by Occurrence $\checkmark$ & $x$ \\
\hline$\square$ Interatomic Distances and Angles & & & 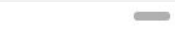 & 812 \\
\hline$\square$ Space Group & & & - & 682 \\
\hline$\square$ Crystal System & & & $=$ & 632 \\
\hline$\square$ Preparation Presence & & & - & 622 \\
\hline$\square$ Reaction & & & - & 622 \\
\hline$\square$ Detailed Reaction Presence & & & $=$ & 621 \\
\hline$\square$ Presence as Product & & & - & 616 \\
\hline$\square$ Crystal Phase & & & $=$ & 607 \\
\hline$\square$ Crystal Property Description & & & $=$ & 576 \\
\hline$\square$ Density & & & $=$ & 567 \\
\hline$\square$ NMR Spectroscopy & & & - & 509 \\
\hline $\begin{array}{lll}1 & 2 & >\end{array}$ & & & Limit to $>$ & ee $>$ \\
\hline
\end{tabular}

Figure S3. Narrowing down the query results by using available data; specifically, only those substances that contain reported NMR Spectroscopy by selecting only "NMR Spectroscopy".

Lastly, using the filter by structure option, complexes that contain the following substructures were excluded, resulting in 449 substances.

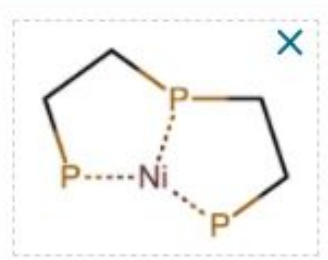

On all atoms

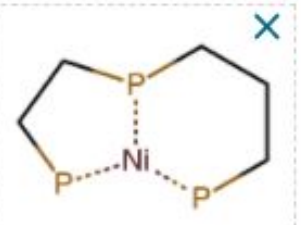

On all atoms

Figure S4. Substructures used as filters to exclude tridentate P ligands. 


\section{b. 3-carbon linker dataset:}

The complexes containing 3-carbon linkers were found via a substructure search using the MarvinJS structure editor in Reaxys. The structure query is shown in Figure S5 and yielded 790 substances:

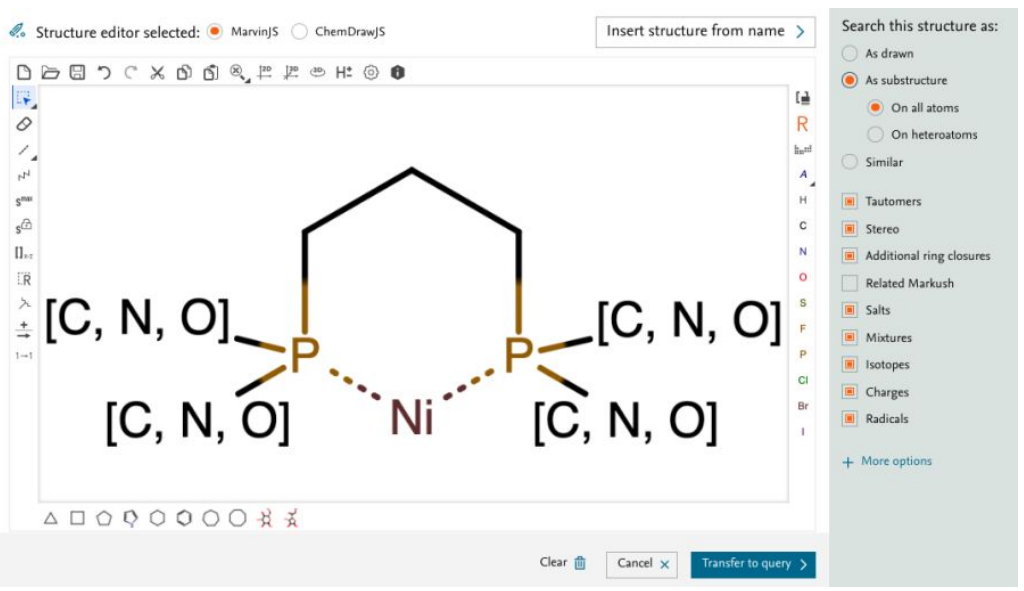

Figure S5. The query used for the substructure search for Ni complexes with 3-carbon linkers. Dotted lines correspond to "any" bond between $\mathrm{P}$ and $\mathrm{Ni}$, and the $[\mathrm{C}, \mathrm{N}, \mathrm{O}]$ enables a search for any substructures that have $\mathrm{P}-\mathrm{C}, \mathrm{P}-\mathrm{N}$, or $\mathrm{P}-\mathrm{O}$ bonds.

The dataset was limited to substances that contain "NMR Spectroscopy" as available data (Figure S6), yielding 388 substances.

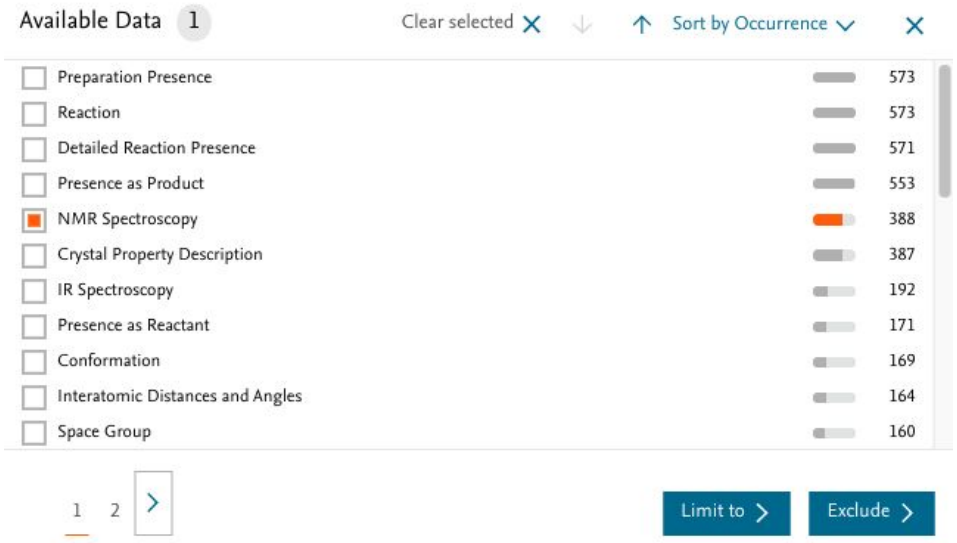

Figure S6. Narrowing down the query results by using available data; specifically, only those substances that contain reported NMR Spectroscopy.

Note on the interatomic distances and angles filter for the datasets: When the 3-carbon linker dataset was limited to structures that also had reported "Interatomic Distances and Angles" (i.e. the same filters as for the 2-carbon linker dataset) the size of the resulting 3-carbon linker dataset was only 52 complexes, the majority of which did not contain a $J_{\mathrm{PP}}$ due to symmetry of the $\mathrm{P}$-atoms across the metal center. After manually processing the dataset to remove complexes that did not have a $J_{P P}$ (vide infra), the final 3-carbon linker dataset only contained 20 complexes (17 $\mathrm{Nill}$ complexes, $3 \mathrm{Ni}^{0}$ complexes). Given the low statistical significance of such a small dataset, the interatomic distances and angles filter was not applied to construct the final 3-carbon dataset. However, because the number of structures in the 2-carbon dataset was sufficiently large with this filter included, and crystal structures enable more reliable assignment of structure and oxidation state, this filter was kept for the 2-carbon dataset. 
Lastly, using the "filter by structure" option, tridentate structures were excluded. This filter excludes many substances that have tetrahedral $\mathrm{Ni}$ (such as complexes bearing triphos type ligands), narrowing the dataset to 272 substances.

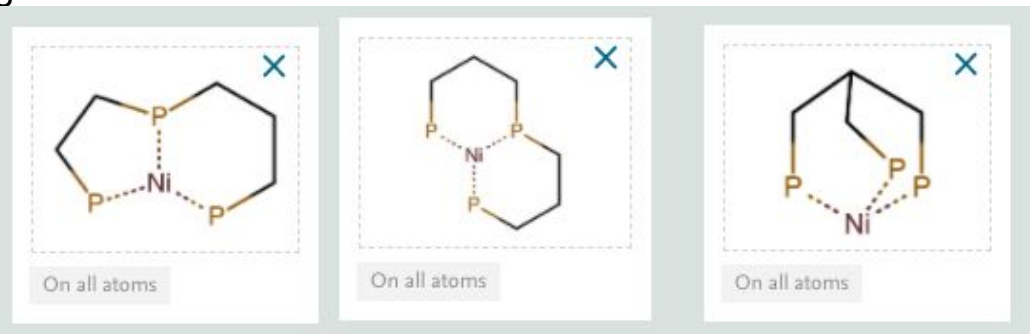

Figure S7. Tridentate substructures used as filter structures to exclude phosphine complexes with trans $J_{\mathrm{Pp}}$ values. 


\section{c. Manual Dataset Processing}

The results of both searches were exported from Reaxys as Microsoft Excel spreadsheets, containing the structure; identifiers; molecular formula; molecular weight; "interatomic distance and angle" information; parameters for NMR spectroscopy such as nucleus, temperature, magnet strength, and solvent; and the references to papers that report the substance. The sheet was sorted in order of increasing molecular weight, then compounds in these sheets were numbered with an ID of the form 2-2\#\#\# (starting from 2-2001) for $2 \mathrm{C}$ complexes and 3-3\#\#\# (starting from 3-3001) for 3C complexes. Then, this sheet was edited to only include structures that contained ${ }^{31} \mathrm{P}$ NMR data (by using the "Nucleus NMR Spectroscopy" column in the exported excel sheet) because the "NMR Spectroscopy" filter applied in the initial substructure search only does not consider the nucleus reported. Numbering the complexes before processing is the reason the compounds in Tables S4 and S5 are not numbered sequentially.

Reaxys does not store NMR data itself in the database, so the $J_{\mathrm{PP}}$ and chemical shifts for each complex were obtained by reading the original journal articles and associated supporting information files. Reaxys did provide information on the "Coupling Nuclei" in the exported Excel sheet, but we found that there were many examples in the datasets where no coupling nucleus was listed, but the actual journal article detailing the compound reported a $J_{\mathrm{PP}}$. Similarly, there were examples where the coupling nucleus listed in the excel sheet was not ${ }^{31} \mathrm{P}$, but a $J_{\mathrm{PP}}$ was reported in the journal article. This error in coupling nucleus most often occurred when $\mathrm{P}$ atoms were coupled to multiple nuclei such as in the case of compounds containing ${ }^{19} \mathrm{~F}$, where there was observable $J_{\mathrm{FP}}$ coupling and $J_{\mathrm{PP}}$ coupling in the ${ }^{31} \mathrm{P}$ NMR spectra. Therefore, we do not recommend using the "coupling nucleus" data provided by Reaxys as a means to filter results in future investigations.

Single crystal XRD data (.cif files) were downloaded from the original journal articles or the Cambridge Crystallographic Data Centre. The oxidation state of the $\mathrm{Ni}$ in each complex was determined by searching for the presence of counterions in the crystal structure and/or counting electrons for each complex based on the Lewis structure. ${ }^{1}$ For the complexes in the 3-carbon linker dataset that did not have single crystal XRD data, the oxidation state at Ni was evaluated by counting electrons for the reported Lewis structure in the original journal articles.

Structures were excluded from the datasets if they satisfied any of the following criteria:

- The complex was symmetric with respect to $\mathrm{C}_{2}$ rotation or reflection of the $\mathrm{P}$ atoms across the metal center, such as for square-planar complexes like $\mathrm{Ni}(\mathrm{dppe}) \mathrm{Cl}_{2}$, tetrahedral complexes like $\mathrm{Ni}(\mathrm{dppp})(\mathrm{CO})_{2}$, or trigonal-planar complexes like $\mathrm{Ni}($ dippe)(ethylene). These types of complexes were excluded because $J$-coupling between $\mathrm{P}$ atoms is not observed in ${ }^{31} \mathrm{P}$ NMR spectra if P-atoms are equivalent. Note: Few tetrahedral complexes remained after this filter because tetrahedral $\mathrm{Ni}$ complexes with symmetric bidentate phosphine ligands have equivalent $P$ atoms regardless of the identities of the trans ligands.

- The complex contained a non-innocent ligand. These complexes were excluded because oxidation state is poorly defined in these systems.

- The ${ }^{31} \mathrm{P}$ NMR spectra contained broad peaks. These complexes were excluded because $\mathrm{J}$ coupling is not resolvable.

- The only $J_{\mathrm{PP}}$ observed was a trans or exocyclic ${ }^{2} J_{\mathrm{PP}}$, such as in $\mathrm{Ni}(\mathrm{dcpe}) \mathrm{PCy}$ or $\mathrm{Ni}(\mathrm{dppe})(\mathrm{dppp}) \mathrm{Cl}_{2}$. These complexes were excluded because these $J_{\mathrm{PP}}$ are expected to arise from different orbital interactions than cis $J_{\mathrm{PP}}$ and are therefore outside the scope of our study. - The ${ }^{31} \mathrm{P}$ NMR spectra contained only one singlet. These complexes were excluded because the presence of only one singlet indicates the structure in solution has a tetrahedral geometry, is not diamagnetic, or is fluxional with respect to geometry at the metal. Treatment of spectra that contained two singlets is detailed below. 
- For the 2-carbon case only, data was excluded if a single crystal X-ray structure could not be found. This occurred when there was an entry for the structure in the Cambridge Crystallographic Database, but no coordinates were available for the entry.

Some structures in the dataset only contained two singlets of equal intensity in reported ${ }^{31} \mathrm{P}$ NMR spectra, but were square planar at $\mathrm{Ni}$ and non-symmetric (i.e., contained $\mathrm{P}$ atoms in the bidentate ligand that had different chemical shifts). In these cases, the J-coupling was recorded as $0.0 \mathrm{~Hz}$. These structures are indicated in Tables S4 and S5 with an asterisk next to the reported $J_{\mathrm{PP}}$ value (e.g., compound 2-2003).

Many journal articles that were found via the Reaxys substructure search contained additional Ni complexes not already in our Reaxys dataset. When these complexes were found, the structures and relevant information were added to our dataset if they satisfied the criteria outlined above (usually with an ID number that contains a trailing letter, e.g., compound 2-2021b). Based on the existence of complexes not included in the original Reaxys search, it is likely that there are many more examples of complexes in literature that belong in this database, but for unknown reasons, these were not found via the Reaxys search.

The final 2-carbon linker dataset contained information on 181 bidentate phosphine $\mathrm{Ni}$ complexes in (Table S4).

The final 3-carbon linker dataset contained information on 51 bidentate phosphine $\mathrm{Ni}$ complexes (Table S5). 


\section{Correlations with experimental ${ }^{31} \mathrm{P}$ chemical shift}

To have an observable $J_{\mathrm{PP}}$ via 1-D ${ }^{31} \mathrm{P}$ NMR spectra, the $\mathrm{P}$ atoms in a complex must not be related by symmetry (However, see reference $S 2$ for a method for obtaining $J_{\mathrm{PP}}$ for symmetric complexes). ${ }^{2}$ Therefore, all complexes in our datasets have two ${ }^{31} \mathrm{P}$ chemical shifts. The ${ }^{31} \mathrm{P}$ chemical shift of $2 \mathrm{C}$ and $3 \mathrm{C}$ complexes are plotted on violin plots (Figure S8).

The results indicate ${ }^{31} \mathrm{P}$ chemical shift is a poor indicator of the oxidation state of Ni bidentate phosphine complexes, given p-values $>0.05$ for comparisons between the $2 \mathrm{C} \mathrm{Ni} / \mathrm{Nill}^{l l}$ datasets and $3 \mathrm{C} \mathrm{Ni} / \mathrm{Ni}^{\prime l}$ datasets (Figure S8) which indicate the distributions are not significantly different. Additionally, the high overlap in ${ }^{31} \mathrm{P}$ chemical shift ranges of $\mathrm{Ni}^{0}$ and $\mathrm{Ni}^{\prime \prime}$ complexes with the same linker length further indicates that ${ }^{31} \mathrm{P}$ chemical shift is a poor indicator of oxidation state.

Small $p$-values and small overlap of ranges was noted when comparing complexes of different linker lengths ( $2 \mathrm{C}$ vs $3 \mathrm{C}$ ) indicating that chemical shift may be an indicator of the linker length. Therefore, use of chemical shift for assignment of linker length may be possible in cases where linker length is unknown (e.g. if ligands with multiple binding modes are used, or if there are multiple ligands of different linker lengths present in the reaction medium).

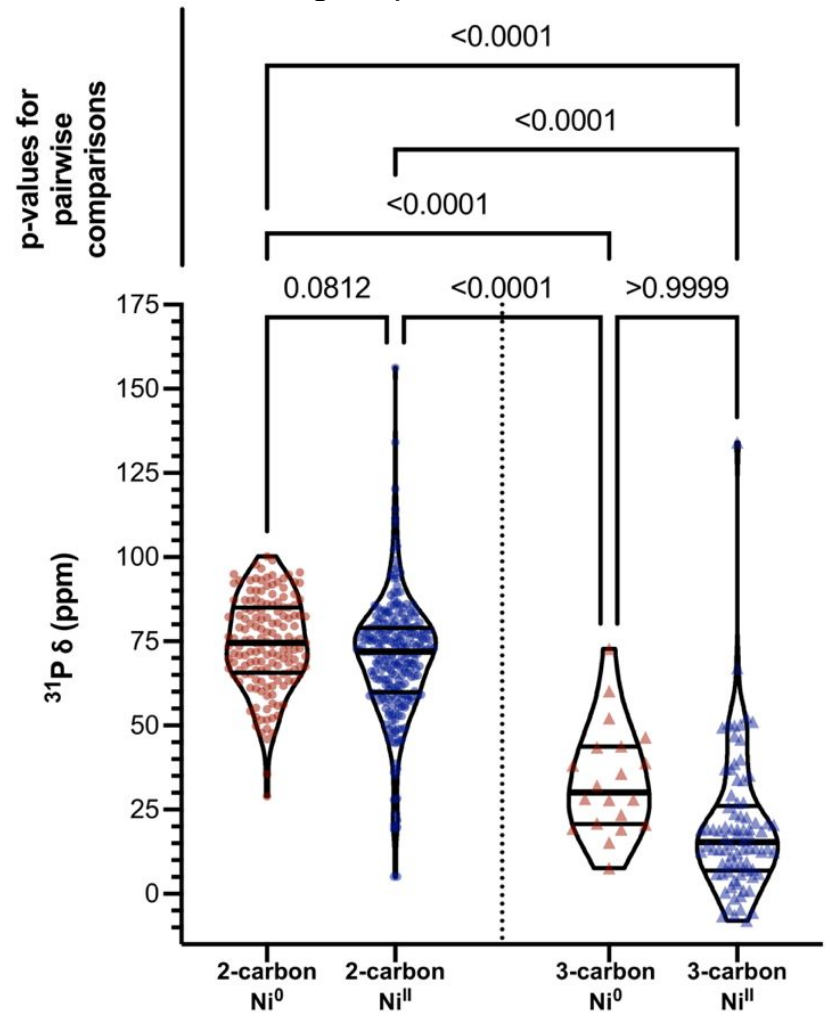

Figure S8. Violin plot of chemical shifts of $2 \mathrm{C}$ and $3 \mathrm{C}$ complexes. All complexes in these datasets showed two separate ${ }^{31} \mathrm{P}$ chemical shifts - both shifts are included in the data above.

No correlation was observed between $\left|J_{\mathrm{PP}}\right|$ or ${ }^{31} \mathrm{P}$ chemical shifts (Figure S9), difference in chemical shifts $\left|\delta_{P_{1}}-\delta_{\mathrm{P} 2}\right|$ (Figure S10), or average chemical shift $\left(\delta_{\mathrm{P}_{1}}+\delta_{\mathrm{P} 2}\right) / 2$ (Figure S11). 


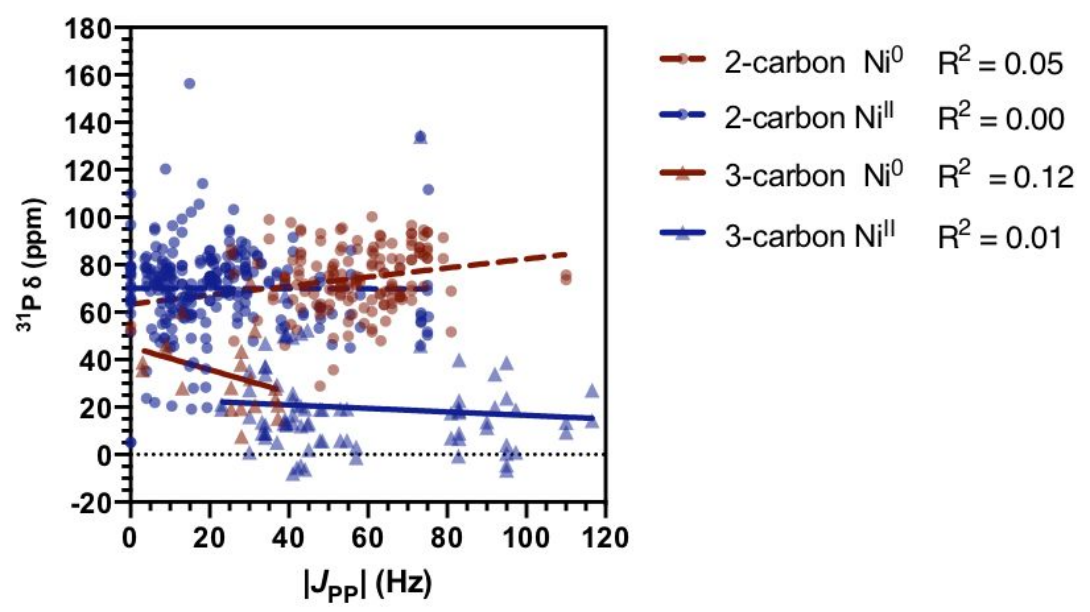

Figure S9. ${ }^{31} \mathrm{P}$ chemical shift versus $\left|J_{\mathrm{PP}}\right|$ for all complexes in the $2 \mathrm{C}$ and $3 \mathrm{C}$ datasets.

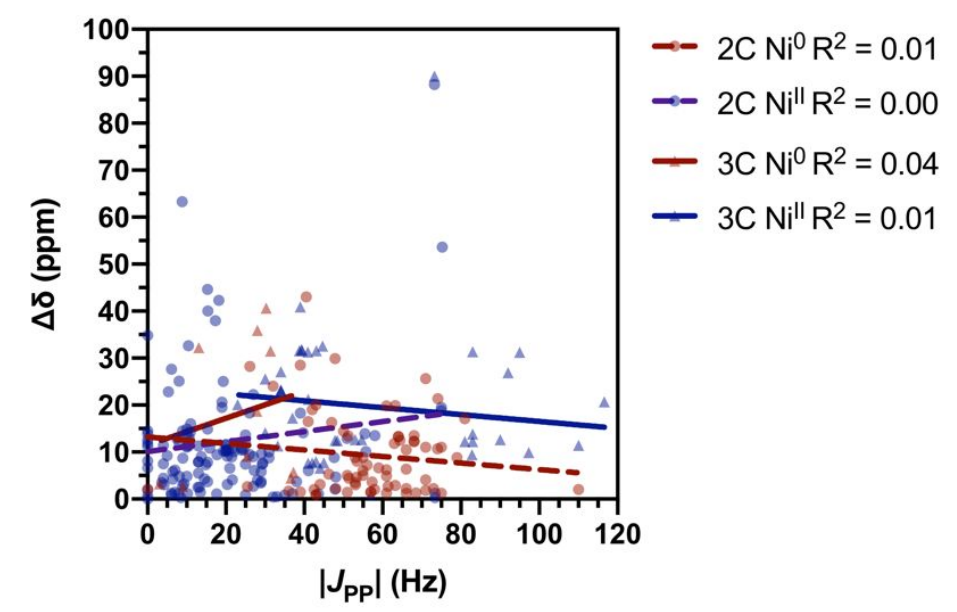

Figure S10. Difference in the two ${ }^{31} \mathrm{P}$ chemical shifts of each complex versus $\left|J_{\mathrm{PP}}\right|$ in the $2 \mathrm{C}$ and $3 \mathrm{C}$ datasets.

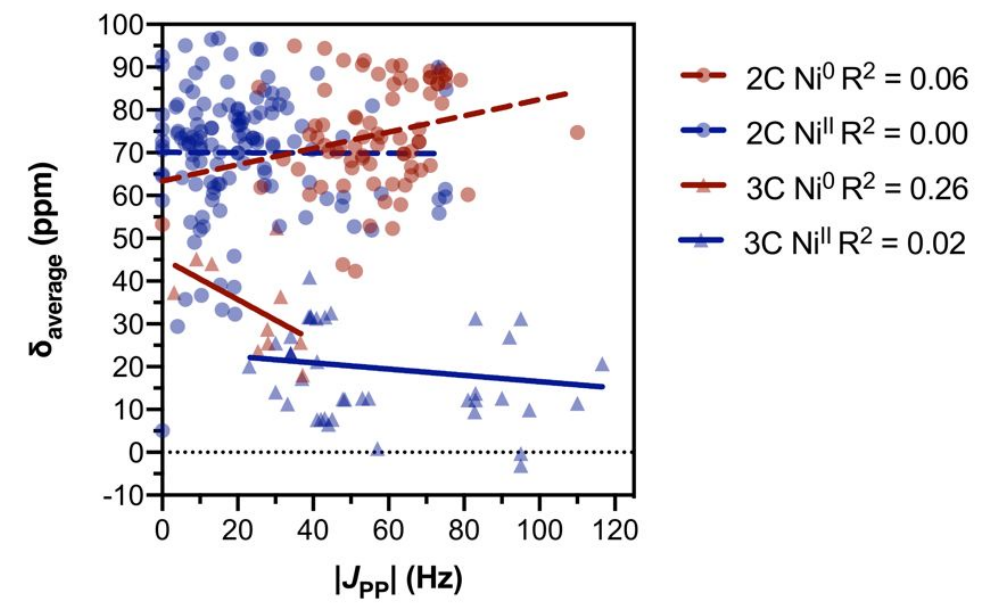

Figure S11. average of the two ${ }^{31} \mathrm{P}$ chemical shifts versus $\left|J_{\mathrm{PP}}\right|$ for each complex in the $2 \mathrm{C}$ and $3 \mathrm{C}$ datasets. 


\section{Computational Details \\ a. Geometry Optimization}

All structures were optimized using Q-Chem $5.1^{3}$ at the DFT level of theory using the O3LYP functional ${ }^{4}$ with the LANL2DZ basis sets and corresponding electron core potentials. ${ }^{5}$ If a crystal structure was available for the desired complex, this structure was used as the input geometry for optimization. If a crystal structure was unavailable, then the proposed Lewis structure for the complex was converted into a 3-dimensional XYZ structure by drawing the structure in Avogadro, and subsequently optimized using the level of theory above. All structures were optimized as singlets - accuracy of this spin state is evidenced by the availability of well-resolved NMR spectra for all complexes in the dataset.

\section{b. Internuclear spin-spin coupling (J-coupling) calculations}

Levels of theory were screened to identify appropriate functional/basis set combinations for internuclear spin-spin coupling calculations (i.e., $J_{\mathrm{PP}}$ calculations). Given the high cost of benchmarking against the entire dataset, a subset of complexes was used for these benchmarks. The results of the benchmarking below led us to the O3LYP functional ${ }^{4}$ for Internuclear spin-spin coupling (ISSC) calculations, with the aug-cc-pVTZ-J basis set on P atoms ${ }^{6}$ and the cc-pVDZ basis set on all other atoms. ${ }^{7}$ Based on analysis of Ramsey contributors, ${ }^{8}$ the Fermi contact contributor to the total $J_{\mathrm{PP}}$ was found to be the largest contributor, and therefore was the only contributor computed for the majority of complexes in the $2 \mathrm{C}$ and $3 \mathrm{C}$ datasets (Tables $\mathrm{S} 4$ and S5). Only isotropic $J_{P P}$ values were used, because only the isotropic $\left|J_{P P}\right|$ value is observed in solution phase NMR spectroscopy.

\section{DFT Functional Benchmarking}

For benchmarking against DFT functionals, Fermi contact $J_{\mathrm{PP}}$ of complexes 2-2002, 22003, 2-2004 and 2-2025 were computed. The basis sets used for these functional screenings consisted of cc-pVDZ ${ }^{7}$ on all atoms, except phosphorus which had aug-cc-pVTZ-J. ${ }^{6}$ All metaGGA functionals available in Q-Chem 5.1 were used for functional screening (functionals from higher rungs of DFT, such as hybrid GGA or hybrid-meta GGA functionals are not compatible with ISSC calculations as implemented in QChem 5.1). Results are in Table S1. RMS error is evaluated based on the differences between the absolute value of the computed $J_{\mathrm{PP}}$ and the value of the observed $J_{\mathrm{PP}}$ (because most experiments only give the magnitude of the $J_{\mathrm{PP}}$, not the sign). This screen revealed that O3LYP was most accurate for these complexes (RMSE $=5.31 \mathrm{~Hz}$ ); the only other functional to give an RMSE less than $10 \mathrm{~Hz}$ was the $\mathrm{B} 97-2$ functional (RMSE $=6.43 \mathrm{~Hz}$ ). While O3LYP and B97-2 are known to be competent functionals for geometry and property prediction in some classes of molecules, it is unknown why these perform particularly well compared to other functionals in computation of $J_{\mathrm{PP}}$ in these systems. 
Table S1. Density functional screen for $J_{\mathrm{pp}}$ calculations, sorted in order of most accurate to least accurate. O3LYP, the functional used for all other $J_{\text {Pp }}$ calculations, is highlighted in green.

\begin{tabular}{|c|c|c|c|c|c|c|c|c|c|}
\hline $\begin{array}{c}\text { DFT } \\
\text { Functional }\end{array}$ & $\begin{array}{c}J_{\mathrm{PP}} \text { for } \\
2- \\
2002 \\
(\mathrm{~Hz})\end{array}$ & $\begin{array}{c}\text { Error } \\
\text { for 2- } \\
2002 \\
(\mathrm{~Hz})\end{array}$ & $\begin{array}{c}J_{\mathrm{PP}} \\
\text { for 2- } \\
2003 \\
(\mathrm{~Hz})\end{array}$ & $\begin{array}{c}\text { Error } \\
\text { for 2- } \\
2003 \\
(\mathrm{~Hz})\end{array}$ & $\begin{array}{c}J_{\mathrm{PP}} \\
\text { for 2- } \\
2004 \\
(\mathrm{~Hz})\end{array}$ & $\begin{array}{c}\text { Error } \\
\text { for 2- } \\
2004 \\
(\mathrm{~Hz})\end{array}$ & $\begin{array}{c}J_{\mathrm{PP}} \text { for } \\
2- \\
2025 \\
(\mathrm{~Hz})\end{array}$ & $\begin{array}{c}\text { Error } \\
\text { for 2- } \\
2025 \\
(\mathrm{~Hz})\end{array}$ & $\begin{array}{l}\text { RMS } \\
\text { error }\end{array}$ \\
\hline $\begin{array}{c}\text { experiment } \\
\text { observed }\left|J_{\mathrm{PP}}\right|\end{array}$ & 9.0 & - & 0.0 & - & 4.0 & - & 20.4 & - & - \\
\hline O3LYP4 & 151 & -4.50 & 711 & 7.41 & 9.61 & & -17.88 & -2.52 & 5.31 \\
\hline $\mathrm{B}$ & 3.72 & & 5.74 & 74 & 14.22 & 0.22 & -25.70 & 5.30 & 6.43 \\
\hline & -3.90 & & 9.31 & 31 & 22.40 & 8.40 & -19.76 & & 10.63 \\
\hline & 0.89 & & 15.48 & 5.48 & 15.40 & 11.40 & -16.11 & & 10.65 \\
\hline & 3.29 & & 10.17 & 0.17 & 25.61 & 21.61 & -19.79 & & 12.28 \\
\hline B3F & .40 & & 20.55 & & 30.16 & & -13.62 & & 17.07 \\
\hline & 6.09 & & 20.75 & & 31.06 & & -12.05 & & 17.61 \\
\hline revPE & 1.66 & & 20.09 & 20.09 & 32.99 & 28.99 & -22.20 & & 18.04 \\
\hline & 3.17 & & 15.56 & & 35.51 & & -14.67 & & 18.04 \\
\hline & .44 & & & & & & & & 18.95 \\
\hline $\mathrm{B} 1 \mathrm{P}$ & 4.43 & & 22.82 & 22.82 & 35.94 & .94 & -19.09 & & 19.77 \\
\hline MPW & 4.63 & & 23.01 & & 36.22 & & -18.63 & & 19.94 \\
\hline MPW1PW91 17 & 4.70 & & 23.04 & 23.04 & 36.52 & & -18.56 & -1.84 & 20.06 \\
\hline B3LYP5 ${ }^{13,18}$ & 10.58 & 1.58 & 24.51 & 24.51 & 36.68 & 32.68 & -6.92 & 13.48 & 21.52 \\
\hline B3LYP13,18 & 10.83 & 1.83 & 24.58 & 24.58 & 36.73 & 32.73 & -6.51 & $\begin{array}{c}- \\
13.89\end{array}$ & 21.63 \\
\hline SOGG & 23.26 & 4.26 & 29.55 & & 32.58 & 8.58 & 15.92 & -4.48 & 21.87 \\
\hline & 10.89 & 1.89 & 25.38 & 25.38 & 39.16 & 35.16 & -7.44 & 12.96 & 22.65 \\
\hline B1LYP16 & 11.16 & 2.16 & 27.61 & 27.61 & 44.48 & 40.48 & -10.01 & $\begin{array}{c}- \\
10.39\end{array}$ & 25.07 \\
\hline MPW1LYP 17 & 11.39 & 2.39 & 27.80 & 27.80 & 45.00 & 41.00 & -9.55 & 10.85 & 25.38 \\
\hline & & & & & & & -48.76 & 28.36 & 26.50 \\
\hline MPW1K 22 & -6.95 & -2.05 & 27.83 & 27.83 & 53.71 & & -52.87 & 32.47 & 32.80 \\
\hline B97-K 23 & 22.25 & 13.25 & 31.07 & 31.07 & 61.16 & 57.16 & -7.61 & 12.79 & 33.81 \\
\hline & -9.22 & & 27.09 & & & & -64.99 & 44.59 & 37.91 \\
\hline & & & & & & & & & 40.97 \\
\hline PBE5025 & -10.80 & 1.80 & 48.27 & 48.27 & 60.29 & 56.29 & -81.19 & 60.79 & 47.95 \\
\hline
\end{tabular}

\section{Basis set benchmarking:}

Basis set benchmarking at the O3LYP level of theory was achieved using a larger set of complexes: 2-2002, 2-2003, 2-2004, 2-2025, 2-2038, 2-2086, 2-2086b, 2-2089, 2-2143b, 22143c. The basis sets ANO-R0, cc-pVDZ, def2-svp, and pc-1, cc-pVDZ + aug-cc-pVTZ-J on P, $c c-p V D Z+p c J-1$ on $P$, and cc-pVDZ + pcJ-2 on P were used with the O3LYP functional in ISSC calculations - exclusion of common basis sets such as $6-31 G^{*}$ and LANL2DZ was due to limitations of Q-Chem 5.1, because the ISSC module is not compatible with basis sets with SP shells or basis sets that require ECPs. Results are in Table S2 - RMS error is evaluated based 
on the differences between the absolute value of the computed $J_{\mathrm{PP}}$ and the value of the observed $\left|J_{\mathrm{PP}}\right|$ (because most experiments only give the magnitude of the $J_{\mathrm{PP}}$, not the sign). The screen revealed that O3LYP/cc-pVDZ + aug-cc-pVTZ-J for $P$ gave the most accurate $\left|J_{P P}\right|$ values compared to experimental values.

Table S2. Benchmarks of basis sets for $J_{\text {PP }}$ calculations (O3LYP functional).

\begin{tabular}{|c|c|c|c|c|c|c|c|c|c|c|c|}
\hline $\begin{array}{c}\text { Basis } \\
\text { set }\end{array}$ & $\begin{array}{c}J_{P P} \\
\text { for } \\
2- \\
2002\end{array}$ & $\begin{array}{c}J_{P P} \\
\text { for } \\
2- \\
2003\end{array}$ & $\begin{array}{c}J_{P P} \\
\text { for } \\
2- \\
2004\end{array}$ & $\begin{array}{c}J_{P P} \\
\text { for } \\
2- \\
2025\end{array}$ & $\begin{array}{c}J_{P P} \\
\text { for } \\
2- \\
2038\end{array}$ & $\begin{array}{c}J_{P P} \\
\text { for } \\
2- \\
2086\end{array}$ & $\begin{array}{c}J_{P P} \\
\text { for } \\
2- \\
2086 \\
b\end{array}$ & $\begin{array}{c}J_{\mathrm{PP}} \\
\text { for } \\
2- \\
2089\end{array}$ & $\begin{array}{c}J_{P P} \\
\text { for } \\
2- \\
2143 \\
b\end{array}$ & $\begin{array}{c}J_{\mathrm{PP}} \\
\text { for } \\
2- \\
2143 \\
\mathrm{c}\end{array}$ & $\begin{array}{l}\text { RMS } \\
\text { error }\end{array}$ \\
\hline $\begin{array}{c}\text { Experiment } \\
\left|J_{\mathrm{PP}}\right|\end{array}$ & 9.0 & 0.0 & 4.0 & 20.4 & 71.0 & 33.0 & 0.0 & 21.5 & 48.0 & 4.0 & - \\
\hline ANO-RO & $\begin{array}{c}119 . \\
9\end{array}$ & $\begin{array}{c}167 . \\
1\end{array}$ & $\begin{array}{c}202 . \\
5\end{array}$ & $\begin{array}{c}169 . \\
1\end{array}$ & $\begin{array}{c}432 . \\
6\end{array}$ & $\begin{array}{c}303 . \\
2\end{array}$ & $\begin{array}{c}126 . \\
2\end{array}$ & $\begin{array}{c}165 . \\
4\end{array}$ & $\begin{array}{c}359 . \\
9\end{array}$ & $\begin{array}{c}126 . \\
2\end{array}$ & $\begin{array}{c}213 . \\
1\end{array}$ \\
\hline cc-pVDZ & -5.0 & 2.7 & -7.6 & -18.5 & 63.1 & 27.9 & -3.7 & -18.7 & 34.8 & 2.2 & 5.7 \\
\hline def2-svp ${ }^{30}$ & -14.3 & -5.2 & -4.6 & -26.8 & 37.0 & 7.6 & -15.4 & -27.5 & 15.3 & -10.6 & 18.1 \\
\hline $\mathrm{pc}-1$ & -12.1 & -1.1 & -5.4 & -27.4 & 57.9 & 19.5 & -11.1 & -28.3 & 27.6 & -6.0 & 10.0 \\
\hline $\begin{array}{c}\text { cc-pVDZ + } \\
\text { aug-cc- } \\
\text { pVTZ-J on } \\
\text { P }\end{array}$ & -6.0 & 4.4 & 3.0 & -19.8 & 68.1 & 26.0 & -5.6 & -20.4 & 36.9 & 0.3 & 5.1 \\
\hline $\begin{array}{l}\text { cc-pVDZ + } \\
\text { pcJ-1 on P }\end{array}$ & -4.2 & 5.9 & 6.0 & -20.1 & 67.1 & 24.6 & -7.3 & -21.0 & 34.6 & -1.4 & 6.2 \\
\hline $\begin{array}{l}\text { cc-pVDZ + } \\
\text { pcJ-2 on P }\end{array}$ & -6.1 & 4.1 & 2.0 & -20.5 & 67.6 & 25.5 & -6.4 & -21.3 & 34.7 & -0.3 & 5.7 \\
\hline
\end{tabular}

\section{Contributors to $J_{\mathrm{PP}}$}

There are four contributors to J-coupling: The Fermi contact (FC) contribution, the paramagnetic spin-orbit contribution (PSO), the diamagnetic spin-orbit contribution (DSO), and the spin-dipole contribution (SD). ${ }^{8}$ The sum of all four contributors gives the total $J$-coupling value. For 43 complexes in our dataset, we utilized Q-Chem to calculate all four contributors to $J_{\mathrm{PP}}$ (Table S3). SD and PSO terms were positive for most $2 \mathrm{C}$ complexes, but negative for $3 \mathrm{C}$ complexes, however, the magnitude of these terms was small, never larger than $2 \mathrm{~Hz}$. The FC term dominated the total, with the remaining terms (PSO, DSO, and SD) combined making up less than $\sim 3 \mathrm{~Hz}$ total contribution to the $J_{\mathrm{PP}}$. This dominance of Fermi contact agrees with other $J_{\mathrm{PP}}$ computations. ${ }^{26,27,28}$ Therefore, only the Fermi Contact term was computed for the remaining complexes. 
Table S3. Ramsey contributors to $J_{\text {PP }}$ for a subset of complexes in this study. Compound numbers refer to complexes in tables S4 and S5.

\begin{tabular}{|c|c|c|c|c|c|c|}
\hline $\begin{array}{c}\text { Compound } \\
\#\end{array}$ & $\begin{array}{l}\text { FC } \\
(\mathrm{Hz})\end{array}$ & $\begin{array}{l}\text { SD } \\
(\mathrm{Hz})\end{array}$ & $\begin{array}{r}\text { PSO } \\
(\mathrm{Hz})\end{array}$ & $\begin{array}{c}\text { DSO } \\
(\mathrm{Hz})\end{array}$ & $\begin{array}{c}\text { Total } J_{\mathrm{PP}} \\
=\mathrm{FC}+\mathrm{SD}+ \\
\mathrm{PSO}+\mathrm{DSO}(\mathrm{Hz})\end{array}$ & $\begin{array}{c}\text { SD + PSO + } \\
\text { DSO } \\
(\mathrm{Hz})\end{array}$ \\
\hline $2-2002$ & -5.990 & 0.956 & 1.237 & 0.260 & -3.537 & 2.453 \\
\hline $2-2003$ & 4.431 & 0.808 & 1.638 & 0.255 & 7.132 & 2.701 \\
\hline $2-2004$ & 3.030 & 0.957 & 1.075 & 0.224 & 5.286 & 2.256 \\
\hline $2-2005$ & -13.838 & 0.708 & 1.979 & 0.256 & -10.895 & 2.943 \\
\hline $2-2019$ & 43.279 & 1.700 & 0.482 & 0.226 & 45.687 & 2.408 \\
\hline $2-2020$ & -20.084 & 0.727 & 1.748 & 0.249 & -17.360 & 2.724 \\
\hline $2-2021$ & 73.619 & 1.976 & 0.111 & 0.229 & 75.935 & 2.316 \\
\hline $2-2021 b$ & -7.703 & 0.999 & 1.109 & 0.268 & -5.327 & 2.376 \\
\hline $2-2022$ & -31.203 & 0.321 & 2.416 & 0.268 & -28.198 & 3.005 \\
\hline $2-2023$ & 47.012 & 1.642 & 0.476 & 0.231 & 49.361 & 2.349 \\
\hline $2-2025$ & -19.794 & 0.849 & 1.612 & 0.284 & -17.049 & 2.745 \\
\hline $2-2032$ & 6.963 & 1.031 & 1.411 & 0.277 & 9.682 & 2.719 \\
\hline $2-2035$ & -26.216 & 0.360 & 2.325 & 0.270 & -23.261 & 2.955 \\
\hline $2-2038$ & 68.147 & 1.525 & -0.188 & 0.223 & 69.707 & 1.560 \\
\hline $2-2046 d$ & 61.451 & 1.967 & 0.258 & 0.232 & 63.908 & 2.457 \\
\hline $2-2046 e$ & -15.624 & 0.658 & 1.667 & 0.270 & -13.029 & 2.595 \\
\hline $2-2086$ & 25.984 & 1.157 & 0.281 & 0.240 & 27.662 & 1.678 \\
\hline $2-2086 b$ & -5.643 & 0.249 & 0.905 & 0.262 & -4.227 & 1.416 \\
\hline $2-2088$ & -1.791 & 0.716 & 1.488 & 0.280 & 0.693 & 2.484 \\
\hline $2-2089$ & -20.362 & 0.871 & 1.670 & 0.288 & -17.533 & 2.829 \\
\hline $2-2090$ & -1.941 & 0.650 & 1.180 & 0.278 & 0.167 & 2.108 \\
\hline $2-2094$ & 45.844 & 1.431 & 0.200 & 0.245 & 47.720 & 1.876 \\
\hline $2-2106$ & 49.323 & 1.581 & 0.186 & 0.246 & 51.336 & 2.013 \\
\hline $2-2107$ & -19.333 & 0.551 & 1.842 & 0.272 & -16.668 & 2.665 \\
\hline $2-2110$ & -22.716 & 0.554 & 1.835 & 0.255 & -20.072 & 2.644 \\
\hline $2-2121$ & -14.408 & 0.809 & 1.755 & 0.255 & -11.589 & 2.819 \\
\hline $2-2122$ & -15.929 & 0.719 & 1.852 & 0.258 & -13.100 & 2.829 \\
\hline $2-2143 b$ & 34.763 & 1.151 & 0.360 & 0.253 & 36.527 & 1.764 \\
\hline $2-2143 c$ & 0.300 & 0.494 & 1.047 & 0.262 & 2.103 & 1.803 \\
\hline $2-2143 e$ & 47.056 & 1.313 & 0.110 & 0.246 & 48.725 & 1.669 \\
\hline $2-2150$ & -14.943 & 0.606 & 1.171 & 0.290 & -12.876 & 2.067 \\
\hline $2-2151$ & -6.861 & 0.647 & 1.179 & 0.287 & -4.748 & 2.113 \\
\hline $2-2172$ & -2.009 & 1.016 & 1.766 & 0.298 & 1.071 & 3.080 \\
\hline $2-2174$ & -22.914 & 0.653 & 1.669 & 0.302 & -20.290 & 2.624 \\
\hline $2-2177$ & -11.466 & 0.622 & 1.922 & 0.287 & -8.635 & 2.831 \\
\hline $2-2202$ & -16.242 & 0.499 & 1.181 & 0.314 & -14.248 & 1.994 \\
\hline $2-2296$ & -17.196 & 0.475 & 1.513 & 0.321 & -14.887 & 2.309 \\
\hline $3-3002$ & -9.314 & -0.227 & 0.069 & 0.135 & -9.337 & -0.023 \\
\hline $3-3007$ & 22.927 & -0.284 & 0.710 & 0.151 & 23.504 & 0.577 \\
\hline $3-3008$ & -25.463 & -0.148 & -0.441 & 0.215 & -25.837 & -0.374 \\
\hline 3-3009 & -40.897 & -0.157 & -0.903 & 0.202 & -41.755 & -0.858 \\
\hline 3-3029 & -84.576 & 0.421 & -1.289 & 0.276 & -85.168 & -0.592 \\
\hline $3-3030$ & -114.755 & 0.137 & -1.356 & 0.233 & -115.741 & -0.986 \\
\hline
\end{tabular}




\section{c. Charge transfer calculations}

Charge transfer was evaluated using the second-generation energy decomposition analysis with absolutely localized molecular orbitals described by Head-Gordon and coworkers and implemented in Q-Chem 5.1. Calculations were performed with the $\omega B 97 M-V$ functional ${ }^{29}$ and def2-SVP basis set. ${ }^{30}$ All molecules in the dataset were fragmented along the P-Ni bonds, giving two fragments: fragment 1 , containing the bidentate phosphine, and fragment 2 , containing the $\mathrm{Ni}$ and all other ligands (Scheme S1). Many cationic complexes were assumed to have a positive charge localized on $\mathrm{Ni}$, therefore, any non-coordinating ions present (such as the BARF anion in 3-3011), were included in Fragment 2 for those structures. Some complexes contain ionic moieties in the phosphine, such as for complex 2-2428, so non-coordinating counterions were included in Fragment 1 in these cases. The spin states of both fragments were assumed singlets. This spin state assignment for the fragments is based on recognizing the unfragmented complexes are singlets due to the existence of well resolved NMR spectra, and that free phosphines (i.e., fragment 1) are generally ground state singlets. Due to the fragmentation scheme, charge transfer values could not be computed for ligands of denticity greater than $\mathrm{K}^{2}$, such as complex 2-2051 and 2-2051a which contain a tridentate ligand.

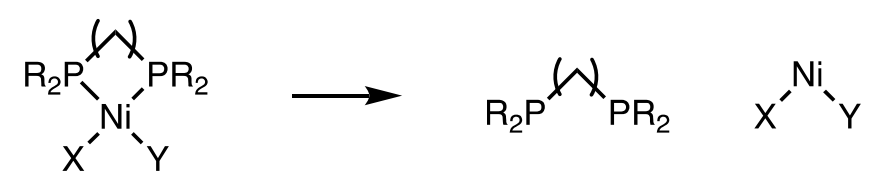

\section{fragment 1 fragment 2 \\ Scheme S1. fragmentation scheme for charge transfer analysis of most complexes.}

The P-to-Ni charge transfer $\left(C T_{\mathrm{P} \text {-to-Ni }}\right)$ in Tables $\mathrm{S} 4$ and S5 refer to the total amount of charge donated from fragment 1 to fragment 2 . The Ni-to-P charge transfer $\left(C T_{\text {Ni-to-P }}\right)$ refers to the total charge donated from fragment 2 to fragment 1. 


\section{Backbonding $C T_{\text {Ni-to-P }}$ Vs. $J_{\mathrm{PP}}$}

There was a weaker correlation observed between $J_{P P}$ and the Ni-to-P charge transfer (Figure S12) than for the correlation of $J_{\mathrm{PP}}$ and $C T_{\mathrm{P} \text {-to-Ni }}$ (Figure 3 in the manuscript). This lower correlation indicates that Ni-to-P backbonding charge transfer is not as good a descriptor of $J_{\mathrm{PP}}$ as the $\sigma$-bonding $\mathrm{P}$-to-Ni charge transfer.

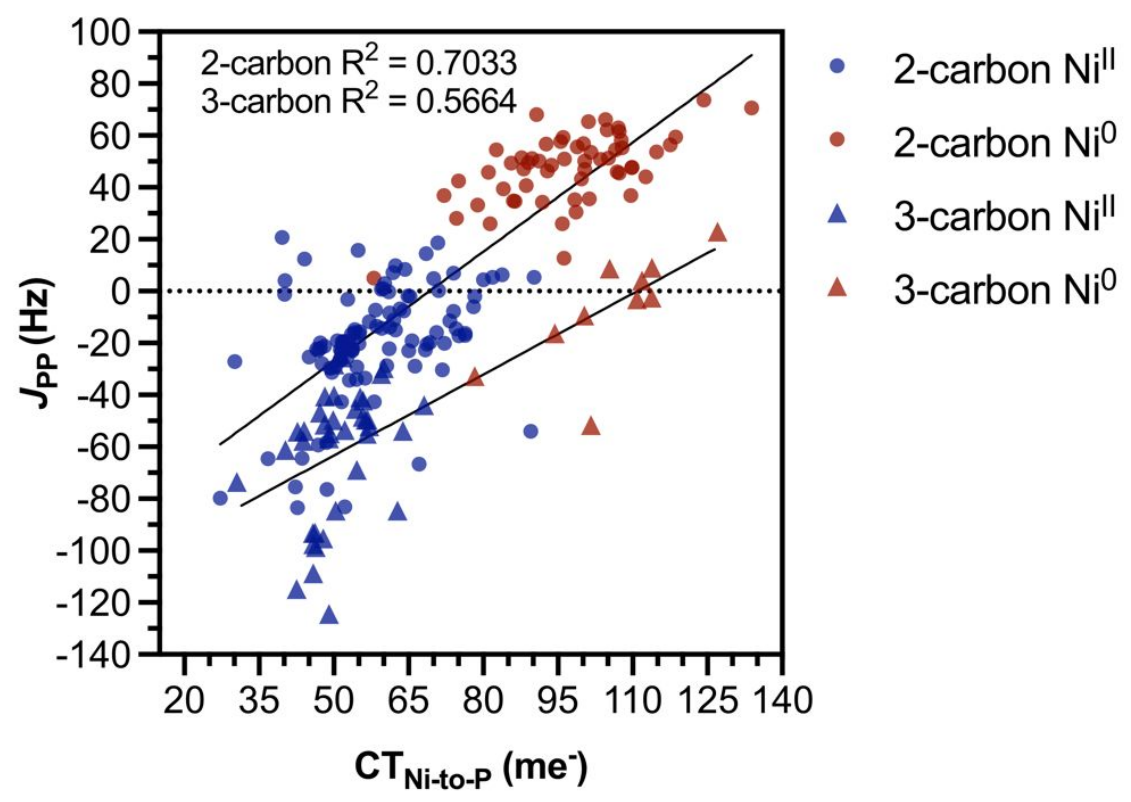

Figure S12. Ni-to-P charge transfer versus $\left|J_{\mathrm{PP}}\right|$ with regression lines shown in black. 


\section{Correlations with Bite Angle and Linker Identity}

\section{Bite angle measurements}

The bite angles discussed below are P-Ni-P angles measured from the available crystal structures. If no crystal structure was available, as was the case with many $3 \mathrm{C}$ complexes, then the $\mathrm{P}-\mathrm{Ni}-\mathrm{P}$ bite angle from the DFT optimized structure was used.

\section{Linker identity correlations with bite angle}

Linker identity and bite angle are clearly linked; when comparing the bite angles of $2 \mathrm{C}$ complexes to bite angles of $3 \mathrm{C}$ complexes the distributions differ significantly $(p<0.0001)$, with $3 \mathrm{C}$ complexes generally having much larger bite angles (Figure S13):

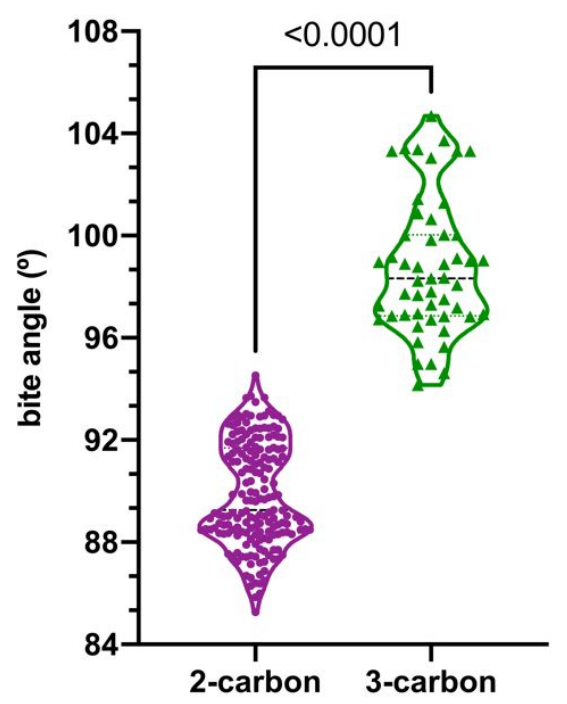

Figure S13. P-Ni-P Bite angle for 2C and 3C complexes.

Within each dataset, however, there was less significant correlation with linker identity. When comparing $2 \mathrm{C}$ complexes containing aliphatic linkers (i.e. all carbons are $\mathrm{sp}^{3}$ hybridized, e.g., ethane linkers) to $2 \mathrm{C}$ complexes containing olefinic linkers (i.e., all carbons are $\mathrm{sp}^{2}$ hybridized, e.g., ethylene and benzene linkers), the distributions overlap significantly (Figure S14) and only differ to a $p$-value $=0.2692$. Similar results are observed when comparing $3 \mathrm{C}$ complexes with aliphatic linkers (e.g., propane linkers) to complexes with olefinic linkers (e.g., naphthalene linkers, acenaphthene linkers, and ligands with fused cyclopentadienyl groups in the backbone like JosiPhos), where the $\mathrm{p}$-value $=0.1831$. These results indicate that the P-Ni-P bite angle is most affected by the number of carbons, and less so by their hybridization. 


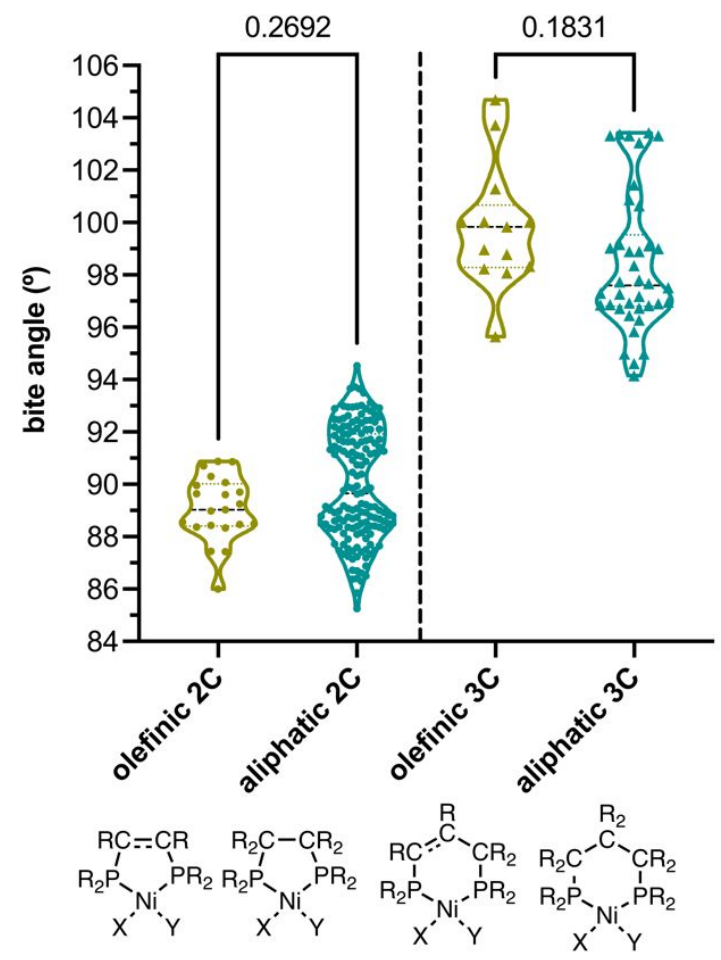

Figure S14. Violin plots for comparison of bite angles between complexes with olefinic and aliphatic $2 \mathrm{C}$ or $3 \mathrm{C}$ linkers.

\section{Chemical Shift correlations with Bite Angle}

For other types of transition metal complexes, there are notable effects of the bite angle on the observed ${ }^{31} \mathrm{P}$ NMR chemical shift. ${ }^{31}$ We investigated the effect of bite angle on the ${ }^{31} \mathrm{P}$ chemical shifts of the complexes in our datasets (Figure S15).

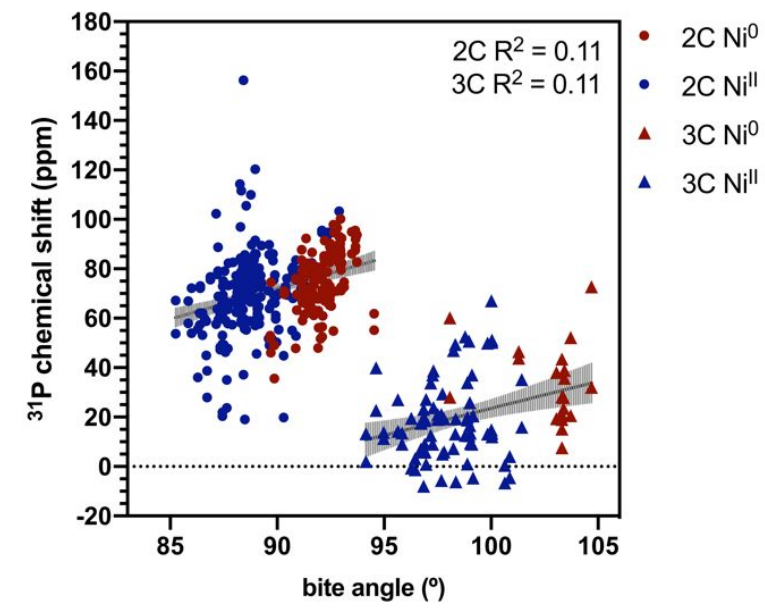

Figure S15. Plot of bite angle vs. chemical shift for 2C and 3C complexes

The effect of linker length on chemical shift is low (Figure S15) and is consistent with the results in Figure S8. Correlations with bite angle are often discussed in terms of ring-size effects, ${ }^{3233}$ with larger bite angles being observed at larger ring sizes. Therefore, the low bite angle/chemical shift correlations observed here likely result from small sampling of ring sizes (i.e., only 2 ring sizes, 5-membered and 6-membered, make up the entire dataset). 


\section{$J_{\mathrm{PP}}$ correlations with Bite Angle}

Correlations between bite angle and calculated $J_{\mathrm{PP}}$ were used to investigate if $J_{\mathrm{PP}}$ is accurately described as a ${ }^{2} \mathrm{~J}$, geminal coupling (Figure S16).

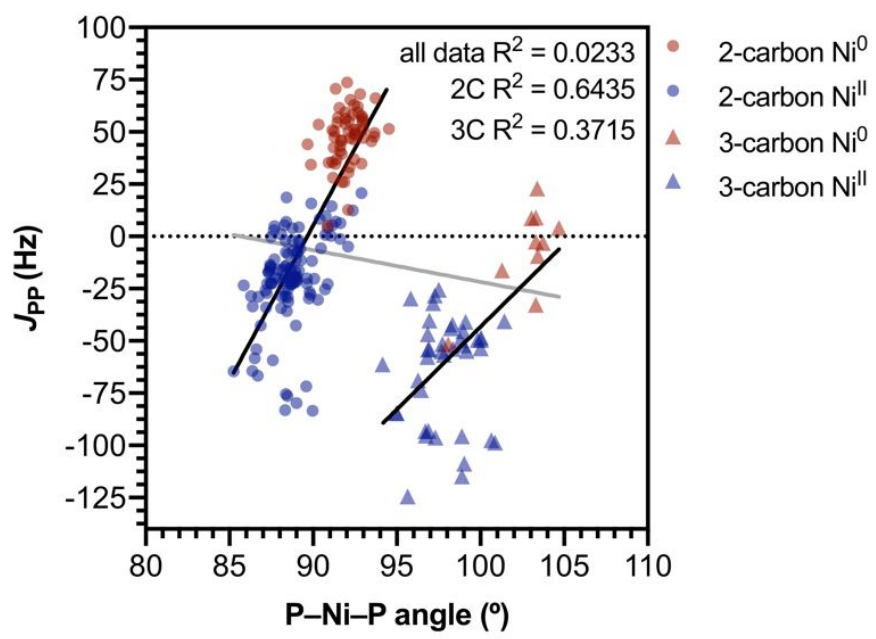

Figure S16. Calculated $J_{\text {Pp }}$ versus P-Ni-P bite angle. Lines of best fit for the 2C and 3C datasets in black, line of best fit for the $2 \mathrm{C}+3 \mathrm{C}$ combined dataset in grey.

Within each dataset, the bite angle correlated moderately with $J_{\mathrm{PP}}$, with worse correlation in the $3 \mathrm{C}$ dataset. This correlation is positive, which is the opposite correlation needed to explain the difference in $J_{P P}$ between $2 \mathrm{C}$ and $3 \mathrm{C}$ complexes (because the $3 \mathrm{C}$ complexes have more negative $J_{\mathrm{PP}}$ and larger bite angles) indicating that the difference in $J_{\mathrm{PP}}$ between $2 \mathrm{C}$ and $3 \mathrm{C}$ complexes is not related to bite angle. If we add the value of $L$ in Eq. 2 (where $L=0 \mathrm{~Hz}$ for $2 \mathrm{C}$ complexes and $L=-48.47 \mathrm{~Hz}$ for $3 \mathrm{C}$ complexes) to all $J_{\mathrm{PP}}$ values to correct for differences in through-linker $J_{P P}$, we can probe the angular dependence of the through-Ni coupling (Figure S17). Still, even when corrected for differences in through-linker coupling by adding $L, \mathrm{R}^{2}$ for the combined dataset is quite low (0.0915) indicating that $J_{P P}$ has a poor dependence on bite angle.

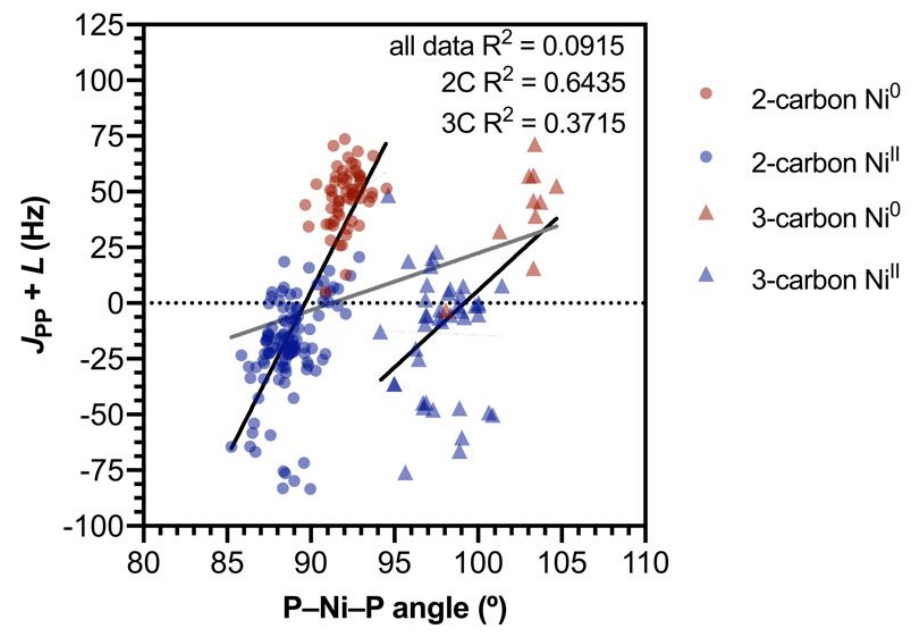

Figure S17. P-Ni-P Bite angle versus $J_{P P}+L$. Lines of best fit for the $2 \mathrm{C}$ and $3 \mathrm{C}$ datasets in black, line of best fit for the $2 \mathrm{C}+3 \mathrm{C}$ combined dataset in grey.

We propose that the correlation of bite angle with $J_{\mathrm{PP}}$ within each dataset arises from the dependence of metal complex geometry on oxidation state, rather than through an angular dependence of $\mathrm{JPP}_{\mathrm{PP}}$. Most $\mathrm{Ni}^{0}$ complexes in our $2 \mathrm{C}$ and $3 \mathrm{C}$ datasets have a NiL${ }_{3}$ structure, favoring 
trigonal planar geometries, with bite angles $>100^{\circ}$. Most Nill complexes however have a $\mathrm{NiL}_{2} \mathrm{X}_{2}$ structure, favoring square planar geometries with bite angles $\sim 90^{\circ}$. Given that $\mathrm{Ni}^{0}$ complexes favor larger bite angles, and $\mathrm{Ni}^{\prime \prime}$ complexes favor smaller bite angles near $90^{\circ}$, the bite angles are partitioned based on oxidation state at $\mathrm{Ni}$, similar to how $J_{\mathrm{PP}}$ partitions by oxidation state, causing an apparent dependence of $J_{\mathrm{PP}}$ and bite angle. This hypothesis of partitioning of the bite angles based on oxidation state is supported by correlations between P-to-Ni charge transfer and P-Ni$\mathrm{P}$ bite angle (Figure $\mathrm{S} 18$ ), which show that complexes with $\mathrm{Ni}^{0}$ have higher bite angles and lower $C T_{\text {P-to-Ni }}$ values than $\mathrm{Nill}^{\prime \prime}$ complexes but shows little correlation beyond oxidation state (i.e. low correlation within each oxidation state/linker length pair).

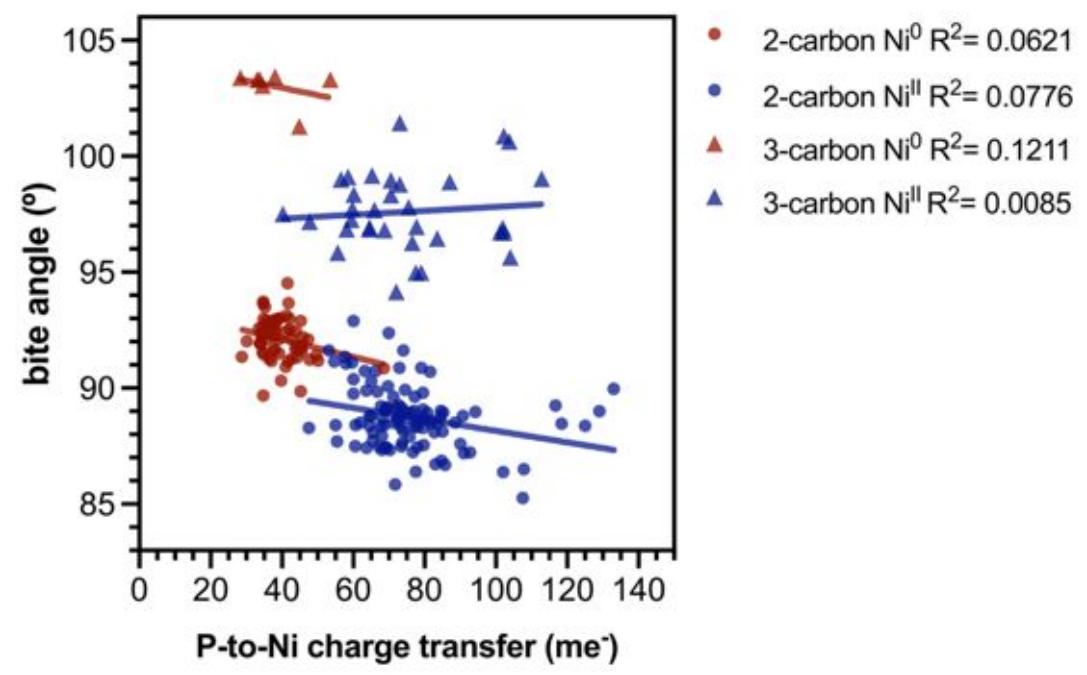

Figure S18. P-Ni-P Bite angle versus P-to-Ni charge transfer. 


\section{References}

${ }^{1}$ Hartwig, J. F. Organotransition Metal Chemistry: From Bonding to Catalysis, 1st ed.; University Science Books: California, 2010; pp 1-26.

2 "The $J_{\mathrm{PP}}$ of symmetric transition metal phosphine complexes can be resolved, but via a combination of NMR spectroscopies. ${ }^{31} \mathrm{P}$ and ${ }^{13} \mathrm{C}$ NMR spectra enable resolving the $J_{\mathrm{PP}}$ of symmetric complexes, as detailed in: Bertrand, R. D.; Ogilvie, F. B.; Verkade, J. G. Signs of Phosphorus-Phosphorus Coupling Constants in Coordination Compounds. J. Am. Chem. Soc. 1970, 92, 1908-1915. Additionally, ${ }^{1} \mathrm{H}$ NMR spectra can also be used to assign $J_{\mathrm{PP}}$, as detailed in" Ogilvie, F. B.; Jenkins, J. M.; Verkade, J. G. ${ }^{11} \mathrm{P} \_{ }^{31} \mathrm{P}$ Spin-Spin Coupling in Complexes Containing Two Phosphorus Ligands. J. Am. Chem. Soc. 1970, 92, 1916-1923.

${ }^{3}$ Shao, Y.; Gan, Z.; Epifanovsky, E.; Gilbert, A. T. B.; Wormit, M.; Kussmann, J.; Lange, A. W.; Behn, A.; Deng, J.; Feng, X.; Ghosh, D.; Goldey, M.; Horn, P. R.; Jacobson, L. D.; Kaliman, I.; Khaliullin, R. Z.; Kús, T.; Landau, A.; Liu, J.; Proynov, E. I.; Rhee, Y. M.; Richard, R. M.; Rohrdanz, M. A.; Steele, R. P.; Sundstrom, E. J.; Woodcock III, H. L.; Zimmerman, P. M.; Zuev, D.; Albrecht, B.; Alguire, E.; Austin, B.; Beran, G. J. O.; Bernard, Y. A.; Berquist, E.; Brandhorst, K.; Bravaya, K. B.; Brown, S. T.; Casanova, D.; Chang, C.-M.; Chen, Y.; Chien, S. H.; Closser, K. D.; Crittenden, D. L.; Diedenhofen, M.; DiStasio Jr., R. A.; Dop, H.; Dutoi, A. D.; Edgar, R. G.; Fatehi, S.; Fusti-Molnar, L.; Ghysels, A.; Golubeva-Zadorozhnaya, A.; Gomes, J.; Hanson-Heine, M. W. D.; Harbach, P. H. P.; Hauser, A. W.; Hohenstein, E. G.; Holden, Z. C.; Jagau, T.-C.; Ji, H.; Kaduk, B.; Khistyaev, K.; Kim, J.; Kim, J.; King, R. A.; Klunzinger, P.; Kosenkov, D.; Kowalczyk, T.; Krauter, C. M.; Lao, K. U.; Laurent, A.; Lawler, K. V.; Levchenko, S. V.; Lin, C. Y.; Liu, F.; Livshits, E.; Lochan, R. C.; Luenser, A.; Manohar, P.; Manzer, S. F.; Mao, S.-P.; Mardirossian, N.; Marenich, A. W.; Maurer, S. A.; Mayhall, N. J.; Oana, C. M.; Olivares-Amaya, R.; O’Neill, D. P.; Parkhill, J. A.; Perrine, T. M.; Peverati, R.; Pieniazek, P. A.; Prociuk, A.; Rehn, D. R.; Rosta, E.; Russ, N. J.; Sergueev, N.; Sharada, S. M.; Sharmaa, S.; Small, D. W.; Sodt, A.; Stein, T.; Stück, D.; Su, Y.-C.; Thom, A. J. W.; Tsuchimochi, T.; Vogt, L.; Vydrov, O.; Wang, T.; Watson, M. A.; Wenzel, J.; White, A.; Williams, C. F.; Vanovschi, V.; Yeganeh, S.; Yost, S. R.; You, Z.-Q.; Zhang, I. Y.; Zhang, X.; Zhou, Y.; Brooks, B. R.; Chan, G. K. L.; Chipman, D. M.; Cramer, C. J.; Goddard III, W. A.; Gordon, M. S.; Hehre, W. J.; Klamt, A.; Schaefer III, H. F.; Schmidt, M. W.; Sherrill, C. D.; Truhlar, D. G.; Warshel, A.; Xua, X.; Aspuru-Guzik, A.; Baer, R.; Bell, A. T.; Besley, N. A.; Chai, J. D.; Dreuw, A.; Dunietz, B. D.; Furlani, T. R.; Gwaltney, S. R.; Hsu, C.-P.; Jung, Y.; Kong, J.; Lambrecht, D. S.; Liang, W.; Ochsenfeld, C.; Rassolov, V. A.; Slipchenko, L. V.; Subotnik, J. E.; Van Voorhis, T.; Herbert, J. M.; Krylov, A. I.; Gill, P. M. W.; Head-Gordon, M. Advances in Molecular Quantum Chemistry Contained in the Q-Chem 4 Program Package. Mol. Phys. 2015, 113, 184-215.

${ }^{4}$ Handy, N. C.; Cohen, A. J. Dynamic Correlation. Mol. Phys. 2001, 99, 607-615.

${ }^{5}$ a) Dunning, T. H.; Hay, P. J. Gaussian Basis Sets for Molecular Calculations in 'Methods of Electronic Structure Theory Modern Theoretical Chemistry $1^{\text {st }}$ ed.; Springer: Berlin, 1977, pp. 1-27.

b) Hay, P. J.; Wadt, W. R. Ab Initio Effective Core Potentials for Molecular Calculations. Potentials for K to Au Including the Outermost Core Orbitals. J. Chem. Phys. 1985, 82, 299-310.

c) Wadt, W. R.; Hay, P. J. Ab Initio Effective Core Potentials For Molecular Calculations. Potentials for Main Group Elements Na to Bi. J. Chem. Phys. 1985, 82, 284-298.

${ }^{6}$ Provasi, P. F.; Sauer, S. P. A. Optimized Basis Sets for the Calculation of Indirect Nuclear Spin-Spin Coupling Constants Involving the Atoms B, Al, Si, P, and Cl. J. Chem. Phys. 2010, 133, 054308.

7 a) Balabanov, N. B.; Peterson, K. A. Systematically Convergent Basis Sets for Transition Metals. I. AllElectron Correlation Consistent Basis Sets for the 3d Elements Sc-Zn. J. Chem. Phys. 2005, 123, 064107.

b) Balabanov, N. B.; Peterson, K. A. Basis Set Limit Electronic Excitation Energies, Ionization Potentials, and Electron Affinities for the 3d Transition Metal Atoms: Coupled Cluster and Multireference Methods. J. Chem. Phys. 2006, 125, 074110.

c) Dunning, T. H. Gaussian Basis Sets for Use in Correlated Molecular Calculations. I. The Atoms Boron Through Neon and Hydrogen. J. Chem. Phys. 1989, 90, 1007-1023.

d) Prascher, B. P.; Woon, D. E.; Peterson, K. A.; Dunning, T. H.; Wilson, A. K. Gaussian Basis Sets for Use in Correlated Molecular Calculations. VII. Valence, Core-Valence, and Scalar Relativistic Basis Sets for Li, $\mathrm{Be}, \mathrm{Na}$, and Mg. Theor. Chem. Acc. 2011, 128, 69-82.

e) Wilson, A. K.; Woon, D. E.; Peterson, K. A.; Dunning, T. H. Gaussian Basis Sets for Use in Correlated Molecular Calculations. IX. The Atoms Gallium through Krypton. J. Chem. Phys. 1999, 110, 7667-7676. 
f) Woon, D. E.; Dunning, T. H. Gaussian Basis Sets for Use in Correlated Molecular Calculations. III. The Atoms Aluminum Through Argon. J. Chem. Phys. 1993, 98, 1358-1371.

${ }^{8}$ Ramsey, N. F. Electron Coupled Interactions between Nuclear Spins in Molecules. Phys. Rev. 1953, 91, $303-307$.

${ }^{9}$ Wilson, P. J.; Bradley, T. J.; Tozer, D. J. Tozer Hybrid Exchange-Correlation Functional Determined from Thermochemical Data and Ab Initio Potentials. J. Chem. Phys. 2001, 115, 9233-9242.

${ }^{10}$ Becke, A. D. Density-Functional Thermochemistry. V. Systematic Optimization of Exchange-Correlation Functionals J. Chem. Phys. 1997, 107, 8554-8560.

11 Wiitala, K. W.; Hoye, T. R.; Cramer, C. J. Hybrid Density Functional Methods Empirically Optimized for the Computation of ${ }^{13} \mathrm{C}$ and ${ }^{1} \mathrm{H}$ Chemical Shifts in Chloroform Solution. J. Chem. Theory Comput. 2006, 2, 1085-1092.

12 Hamprecht, F. A.; Cohen, A. J.; Tozer, D. J.; Handy N. C. Handy Development and Assessment of New Exchange-Correlation Functionals. J. Chem. Phys. 1998, 109, 6264-6271.

${ }^{13}$ Becke, A. D. Density-Functional Thermochemistry. III. The Role of Exact Exchange. J. Chem. Phys. 1993, 98, 5648-5652.

${ }^{14}$ Adamo, C. Toward Reliable Density Functional Methods Without Adjustable Parameters: The PBE0 Model. J. Chem. Phys. 1999, 110, 6158-6170.

${ }^{15}$ Keal. T. W.; Tozer, D. J. Semiempirical Hybrid Functional with Improved Performance in an Extensive Chemical Assessment. J. Chem. Phys. 2005, 123, 121103.

${ }^{16}$ Adamo, C.; Barone, V. Toward Reliable Adiabatic Connection Models Free from Adjustable Parameters. Chem. Phys. Lett. 1997, 274, 242-250.

17 Adamo, C.; Barone, V. Exchange Functionals with Improved Long-Range Behavior and Adiabatic Connection Methods Without Adjustable Parameters: The mPW and mPW1PW Models. J. Chem. Phys. 1998, 108, 664-675.

18 Stephens, P. J.; Devlin, F. J.; Chabalowski, C. F.; Frish, M. J. Ab Initio Calculation of Vibrational Absorption and Circular Dichroism Spectra Using Density Functional Force Fields. J. Phys. Chem. 1994, 98, 11623-11627.

19 Peverati, R.; Truhlar, D. G. Communication: a Global Hybrid Generalized Gradient Approximation to the Exchange-Correlation Functional that Satisfies the Second-Order Density-Gradient Constraint and has Broad Applicability In Chemistry. J. Chem. Phys. 2011, 135, 191102.

${ }^{20}$ Xu, X.; Goddard III, W. A. The X3LYP Extended Density Functional for Accurate Descriptions of Nonbond Interactions, Spin States, and Thermochemical Properties. Proc. Natl. Acad. Sci. U.S.A. 2003, 101, 2673-2677.

${ }^{21}$ Grimme, S.; Brandenberg, J. G.; Bannwarth, C.; Hansen, A. Consistent Structures and Interactions by Density Functional Theory with Small Atomic Orbital Basis Sets. J. Chem. Phys. 2015, 143, 054107.

22 Lynch, B. J.; Fast, P. L.; Harris, M.; Truhlar, D. G. Adiabatic Connection for Kinetics. J. Phys. Chem. A 2000, 104, 4811-4815.

${ }^{23}$ Boese, A. D.; Martin, J. M. L. Development of Density Functionals for Thermochemical Kinetics. J. Chem. Phys. 2004, 121, 3405-3416.

${ }^{24}$ Shao, Y.; Head-Gordon, M.; Krylov, A. I. The Spin-Flip Approach Within Time-Dependent Density Functional Theory: Theory and Applications to Diradicals. J. Chem. Phys. 2003, 118, 4807-4818.

${ }^{25}$ Bernard, Y. A.; Shao, Y.; Krylov, A. I. General Formulation of Spin-Flip Time-Dependent Density Functional Theory Using Non-Collinear Kernels: Theory, Implementation, and Benchmarks. J. Chem. Phys. 2012, 136, 204103.

${ }^{26}$ Burk, S.; Götz, K.; Kaupp, M.; Nieger, M.; Weber, J.; Schmedt auf der Günne, J.; Gudat, D. Diphosphines with Strongly Polarized P-P Bonds: Hybrids between Covalent Molecules and DonorAcceptor Adducts with Flexible Molecular Structures. J. Am. Chem. Soc. 2009, 131, 10763-10774.

${ }^{27}$ Forgeron, M. A. M.; Gee, M.; Wasylishen, R. E. A Theoretical Investigation of One-Bond Phosphorus-Phosphorus Indirect Nuclear Spin-Spin Coupling Tensors, ${ }^{1} \mathrm{~J}\left({ }^{31} \mathrm{P},{ }^{31} \mathrm{P}\right)$, Using Density Functional Theory. J. Phys. Chem. A 2004, 108(22), 4895-4908.

${ }^{28}$ Huynh, K., Lough, A. J.; Forgeron, M. A. M.; Bendle, M.; Soto, A. P.; Wasylishen, R. E.; Manners, I. Synthesis and Reactivity of Phosphine-Stabilized Phosphoranimine Cations, [R3P.PR'2dNSiMe3]+. J. Am. Chem. Soc. 2009, 131, 7905-7916. 
29 Mardirossian, N.; Head-Gordon, M. wB97M-V: A Combinatorially Optimized, Range-Separated Hybrid, Meta-GGA Density Functional With VV10 Nonlocal Correlation. J. Chem. Phys. 2016, 144, 214110.

30 a) Metz, B.; Stoll, H.; Dolg, M. Small-Core Multiconfiguration-Dirac-Hartree-Fock-Adjusted Pseudopotentials for Post- $d$ Main Group Elements: Application to PbH And PbO. J. Chem. Phys. 2000, 113, 2563-2569. b) Peterson, K. A.; Figgen, D.; Goll, E.; Stoll, H.; Dolg, M. Systematically Convergent Basis Sets with Relativistic Pseudopotentials. II. Small-Core Pseudopotentials and Correlation Consistent Basis Sets for the Post-d Group 16-18 Elements. J. Chem. Phys. 2003, 119, 11113-11123. c) Weigend, F.; Alrichs, R. Balanced Basis Sets of Split Valence, Triple Zeta Valence and Quadruple Zeta Valence Quality for H To Rn: Design and Assessment of Accuracy. Phys. Chem. Chem. Phys. 2005, 7, 32973305.

${ }^{31}$ For an example, compare the 31P NMR chemical shifts of complexes in: Petzold, H.; Görls, H.; Weigand, W. A simple and efficient synthesis of bisphosphine platinum(0) complexes with various P-PtP angles. J. Organomet. Chem. 2007, 262, 2736-2742.

32 Kühl, O. Phosphorus-31 NMR Spectroscopy; Springer-Verlag, Berlin, 2008; pp 7-12, 16-22.

${ }^{33}$ Pregosin, P. S. NMR in Organometallic Chemistry; Wiley-VCH: Weinheim, 2012; pp 168-170. 